\title{
In Situ Observation of Liquid-Liquid Phase Separation of Glass under Microgravity
}

\author{
Yuji MINAMI, Akio MAKISHIMA, Akira TANJI, ${ }^{*}$ Tomoya KONISHI** and Satoru INOUE** \\ Center for Nano Materials and Technology, Japan Advanced Institute of Science and Technology, \\ 1-1, Asahidai, Nomi-shi, Ishikawa 923-1292 \\ *Japan Space Utilization Promotion Center, 3-30-16, Nishiwaseda, Shinjuku-ku, Tokyo 169-8624 \\ **Advanced Materials Laboratory, National Institute for Materials Science, 1-1, Namiki, Tsukuba-shi, Ibaraki 305-0044
}

\author{
微小重力環境下におけるガラスの液-液分相のその場観察 \\ 南 祐二·牧島亮男 $\cdot$ 丹治 章* · 小西智也 ${ }^{* *} \cdot$ 井上 悟** \\ 北陸先端科学技術大学院大学ナノマテリアルテクノロジーセンター, 923-1292 石川県能美市旭台 1-1 \\ *宇宙環境利用推進センター, 169-8624 東京都新宿区西早稲田 3-30-16 \\ **物質・材料研究機構物質研究所, 305-0044 茨城県つくば市並木 1-1
}

\begin{abstract}
We succeeded in the in situ observation of liquid-liquid phase separation of glass under microgravity at the Japan Microgravity Center (JAMIC), which provides a $10 \mathrm{~s}$ microgravity duration. The microgravity level is $10^{-5} \mathrm{~g}$ ( $\mathrm{g} \equiv$ gravitational field at Earth's surface). We constructed an apparatus for the observation of phase separation suitable for the experimental facility. The melt of $3 \mathrm{BaO} \cdot 97 \mathrm{~B}_{2} \mathrm{O}_{3}(\mathrm{~mol} \%)$ was held as a film on a Pt wire loop. The sample was initially heated above the immiscibility temperature and held at that temperature. After the homogenization stage, the melt was cooled. Liquid-liquid phase separation of the melt was observed directly with a video camera. It was found that the nucleation and growth of phase-separated particle under microgravity are slower than in the case of $1-\mathrm{g}$, and the delay time of phase separation between the case of microgravity and 1-g depends on the flow rate of the melt under microgravity. These observations could be interpreted in terms of Marangoni convection and a change of diffusion.
\end{abstract}

[Received April 13, 2005; Accepted July 21, 2005]

Key-words : Phase separation, Microgravity, In situ observation, Nucleation and growth, $\mathrm{BaO}, \mathrm{B}_{2} \mathrm{O}_{3}$

\section{Introduction}

Liquid-liquid phase separation is a phenomenon in which a uniform molten glass decomposes into two liquid phases when heat-treated at a temperature below an immiscibility boundary. ${ }^{1)}$ The binary borate systems, such as $\mathrm{MgO}-\mathrm{B}_{2} \mathrm{O}_{3}, \mathrm{CaO}-$ $\mathrm{B}_{2} \mathrm{O}_{3}, \mathrm{SrO}-\mathrm{B}_{2} \mathrm{O}_{3}, \mathrm{BaO}-\mathrm{B}_{2} \mathrm{O}_{3}$, and $\mathrm{PbO}-\mathrm{B}_{2} \mathrm{O}_{3}$, are typical examples for which droplets of hundreds of nanometers to tens of micrometers in diameter are dispersed in a matrix. ${ }^{1,2)}$ Inoue et al. suggested an approach to derive new glasses through liquid-liquid phase separation. ${ }^{3)}$ Recently, optical functional glass, such as rare-earth-ion-containing glass microshpere is being made by liquid-liquid phase separation. ${ }^{4)}$

However, this phenomenon is accompanied by substance movement in the liquid state, and it tends to be influenced by gravity compared with phase separation which takes place in the solid state. So depending on composition of glass, matrix and phase-separated particle separate up and down because of their difference in weight. ${ }^{5), 6)}$

A microgravity environment offers such merits as a decrease of thermal convection, decrease of static pressure, and no sedimentation. ${ }^{7)}$ Therefore the microgravity environment is expected to give uniform dispersion of highly spherical particles in liquid-liquid phase separation. We have carried out the in situ observation of the liquid-liquid phase separation of glass in the drop-shaft experiment facility, using original in situ observation equipment, in MGLAB at Toki which provides a duration of $3 \mathrm{~s}$ of microgravity of $10^{-5} \mathrm{~g} .{ }^{8), 9)}$

In this study, we aimed at establishing an in situ observation method of liquid-liquid phase separation of glass using the JAMIC facility that can provide $10 \mathrm{~s}$ of microgravity. This duration is the longest microgravity time in the world for a dropshaft experimental facility. We studied the nucleation and growth of phase-separated particle by an in situ observation method.

\section{Experimenta}

The glass of the $\mathrm{BaO}-\mathrm{B}_{2} \mathrm{O}_{3}$ system was prepared by a meltquenching method. The batch composition was $3 \mathrm{BaO} \cdot 97 \mathrm{~B}_{2} \mathrm{O}_{3}$ $(\mathrm{mol} \%)$. The batch for glass was prepared as a mixture of reagents weighed suitably for the composition. The batch was melted in a Pt crucible at a temperature higher than the immiscibility temperature in an electric furnace. The melt was quenched to a glassy frit by squeezing it between two carbon blocks.

The experimental facility that we utilized is located at the Japan Microgravity Center (JAMIC) in Kamisunagawa, Hokkaido. The system provides a $10 \mathrm{~s}$ microgravity duration, which is the longest in the world for a drop-shaft experimental facility, and the microgravity level is $10^{-5} \mathrm{~g}$. We have made the apparatus for the observation of phase separation suitable for the experimental facility.

Figure 1 shows the block diagram of the setup for the in situ observation of phase separation. The melt of $3 \mathrm{BaO} \cdot 97 \mathrm{~B}_{2} \mathrm{O}_{3}$ $(\mathrm{mol} \%)$ was held as a film on a $\mathrm{Pt}$ wire $(0.5 \mathrm{~mm}$ in a diameter) loop of about $3 \mathrm{~mm}$ in outer diameter. A sample glass flake was placed on the Pt wire loop that was heated by applying current to the wire, and then melted and held as a film on a Pt loop. The thickness of the sample film was calculated to be about $0.5 \mathrm{~mm}$ by dividing the mass of the melt by the area of the loop. The Pt loop with a sample film was heated in a Pt wire bobbin heater. The inside of the test chamber including the sample setup was purged with Ar gas. The junction of a Pt-Pt13\% Rh thermocouples was welded to the Pt loop to detect the temperature of the sample holding loop. The ther- 


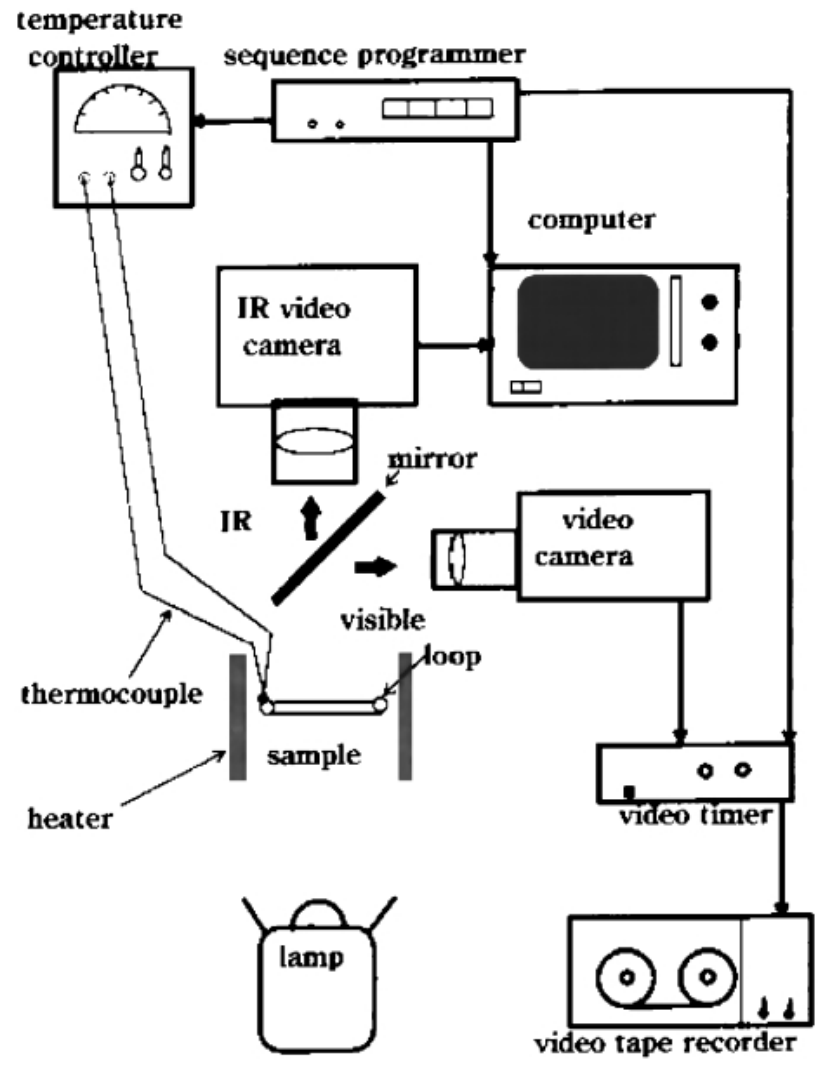

Fig. 1. Block diagram of the setup for the in situ observation of phase separation.

mocouples was connected to a temperature controller. The light transmitted through the film was split into visible light and infrared light by a multicoated Si-mirror. The visible light was guided to a video camera to be recorded as video movies. The field of view of the video camera is $200 \mu \mathrm{m}$ in width by $155 \mu \mathrm{m}$ in height.

The sample was initially heated above the immiscibility temperature and held for a few minutes to homogenize the melt. After the homogenization stage, the melt was cooled at fixed cooling rate. Immediately after the computer received the drop signal, the output power of the temperature controller was turned off to cool the sample at an appropriate rate.

Prior to the experiment under microgaravity, the work of the sequencer was tested by running the sequence program at $1 \mathrm{-g}$, in which phase separation was observed, and the image was recorded as the reference.

\section{Result}

3.1 Video snapshots of liquid-liquid phase separation of glass under microgravity

Figure 2 shows the video snapshots of the liquid-liquid phase separation of glass under microgravity. After dropping for $4.0 \mathrm{~s}$, the liquid-liquid phase separation had not yet started. After dropping for $6.0 \mathrm{~s}$, the precipitation of phase-separated particle of micron order is observed. After dropping for $7.0 \mathrm{~s}$, phase-separated particles cover the whole screen. After dropping for $9.0 \mathrm{~s}$, the screen is dark as a result of optical dispersion due to many phase-separated particles precipitated.

3.2 Comparison of start of phase-separated particle precipitation between under microgravity and under $1-\mathrm{g}$

Figure 3 shows the comparison of start of phase-separated particle precipitation between under microgravity and under 1-g. This figure denotes the video snapshots of liquid-liquid phase separation of glass. Under microgravity, a change in the picture of the precipitation of phase-separated particle is seen $6.0 \mathrm{~s}$ after the start of the drop. Under 1-g, a change in the picture of the precipitation of phase-separated particle is seen 4.5 $\mathrm{s}$ after the start of the drop. In this study, the start of phaseseparated particle precipitation under microgravity appeared to be slower than that under $1-\mathrm{g}$.

In this microgravity experiment, it was observed that phaseseparated particles marked with a black circle after dropping for $4.0 \mathrm{~s}$ and $8.0 \mathrm{~s}$ hardly moves, as shown in Fig. 4. Therefore, the flow is almost zero in melt under microgravity. On the other hand, a flow of precipitated particles is observed in melt under 1-g (Fig. 5).

Figure 6 shows the relationship between the flow rate of the melt under microgravity and the delay time of phase separation under microgravity relative to the phase separation under 1-g. The observed delay time was always positive. The flow rate was not controlled and was evaluated from the movement of phase-separated particle. The broken line in Fig. 6 was obtained by the method of least squares. When the flow rate under microgravity becomes higher, the start time of the precipitation of phase-separated particle under microgravity approaches that under $1-\mathrm{g}$. When the flow rate under microgravity becomes very high, the delay time becomes almost $0 \mathrm{~s}$. When the flow rate under microgravity is $0 \mu \mathrm{m} / \mathrm{s}$, the precipitation of phase-separated particles is slower by about $1.5 \mathrm{~s}$ compared with case of the 1 -g.

\section{Discussion}

Under a microgravity environment, it is known that Marangoni convection may be generated. Tsukamoto et al. carried out in situ observation of crystal growth from the solution under a microgravity environment. ${ }^{10)}$ They found an anisotropic growth rate of the crystal in a microgravity environment. Growth rate anisotropy of the crystal was exaggerated due to Marangoni convection that occurs near the seed crystal. Although the minimal growth rate under microgravity was lower than the rate under $1-\mathrm{g}$, the maximal growth rates were nearly the same as that under $1-\mathrm{g}$.

The liquid-liquid phase separation has a mechanism similar to that of crystal growth. Therefore, the flow of the melt observed in this study seems to occur by Marangoni convection. The flow rate by Marangoni convection observed by Tsukamoto et al. was from $0.1 \mathrm{~mm} / \mathrm{s}$ to $1 \mathrm{~mm} / \mathrm{s}$, but the flow rate by Marangoni convection observed in this study was from $0 \mu \mathrm{m} / \mathrm{s}$ to $44 \mu \mathrm{m} / \mathrm{s}$, which is much lower than those reported by Tsukamoto et al. It is considered that Marangoni convection is suppressed as a result of adopting the indirect heating method for the heating of the sample in this study. ${ }^{9)}$ This indirect heating method enabled uniform heating of the sample. On the other hand, Tsukamoto et al. adopted the direct heating method for the heating of the sample. ${ }^{10)}$

Marangoni convection induced by surface tension becomes nonuniform due to the presence of temperature and concentration gradients in the surface. In this study, the in situ observation equipment seems to have a uniform temperature gradient, because the temperature remains uniform. ${ }^{9}{ }^{9}$ Therefore, Marangoni convection seems to be induced by the presence of the concentration gradient in the phase separation process.

The liquid-liquid phase separation is, as in the case of the nucleation and growth of crystal, the process of nucleation of a new phase and its subsequent growth. The mass transport at 
the phase boundary between the nucleus and the liquid is diffusion-controlled, which they considered to be an activated process.

The rate of steady-state homogeneous nucleation can then be expressed as

$$
I_{0}=n \frac{D}{\lambda^{2}} \exp \left(-\frac{\Delta G^{*}}{k T}\right),
$$

where $D$ is the diffusion rate constant characterizing the mass
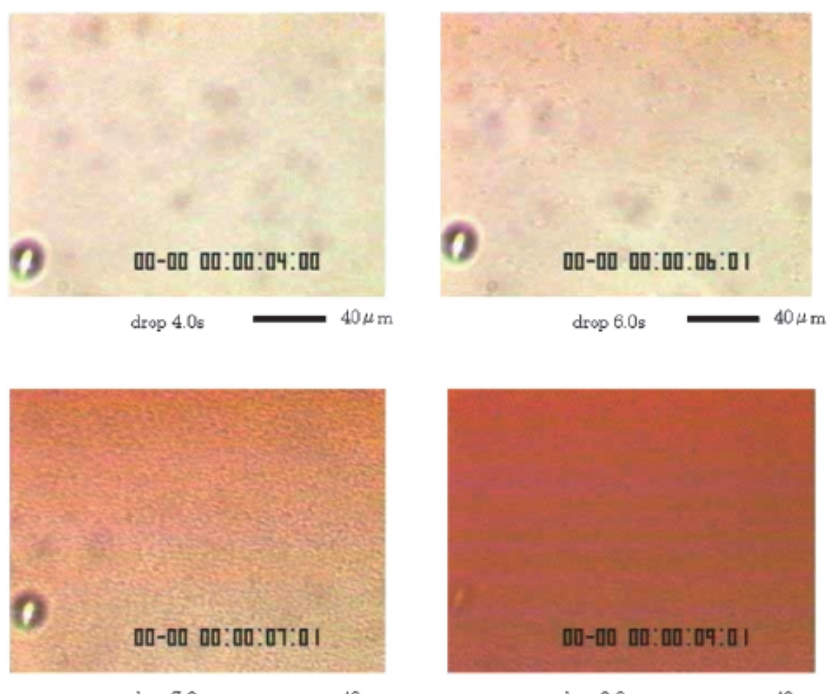

drop $7.0 \mathrm{~s}$

$-\longrightarrow 40 \mathrm{~m}$

drop $9.0 s$

Fig. 2. Video snapshots of the liquid-liquid phase separation of glass under microgravity. transport across the phase boundary, $n$ is the number of molecules per unit volume in the initial phase, $\lambda$ is the molecular diameter, $\Delta G^{*}$ represents the thermodynamic barrier to homogeneous nucleation.
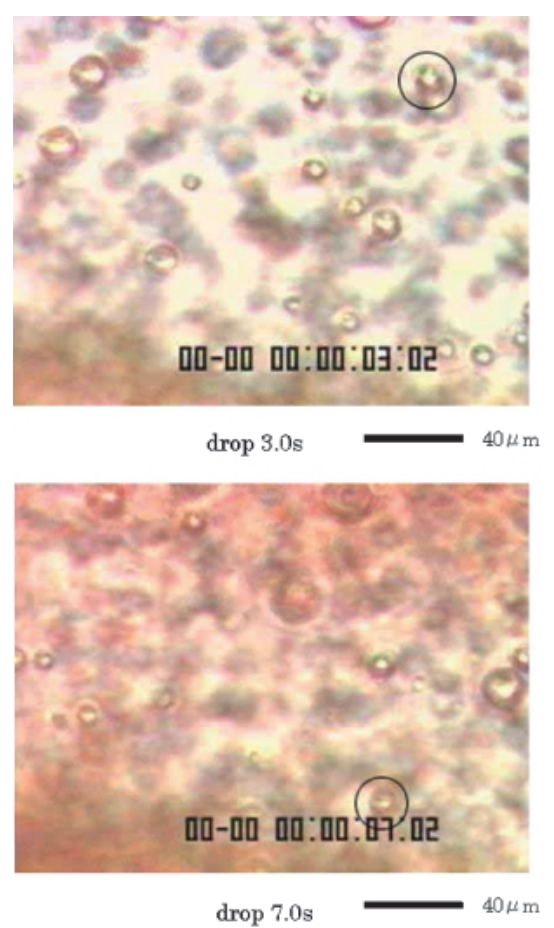

Fig. 5. Video snapshots of liquid-liquid phase separation of glass under 1 -g (after dropping for $3.0 \mathrm{~s}$ and $7.0 \mathrm{~s}$ ).
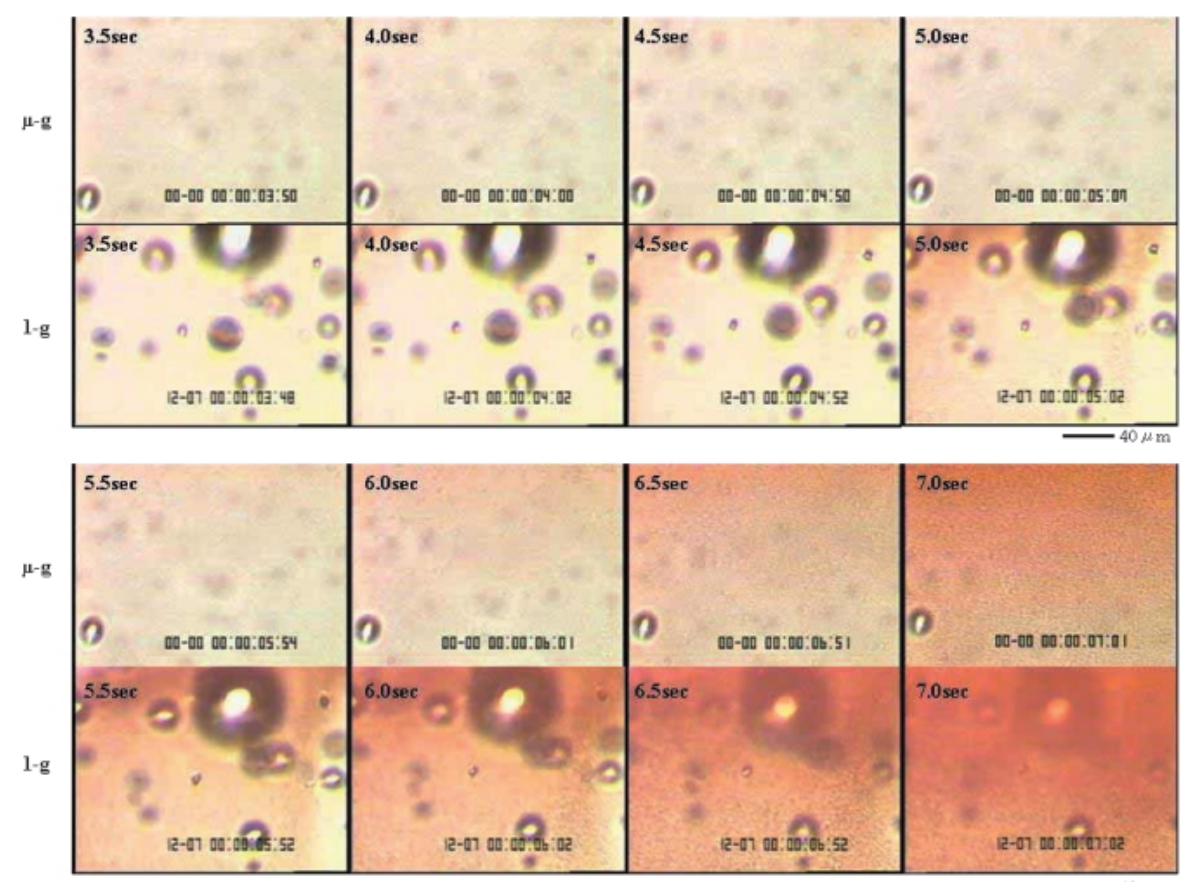

Fig. 3
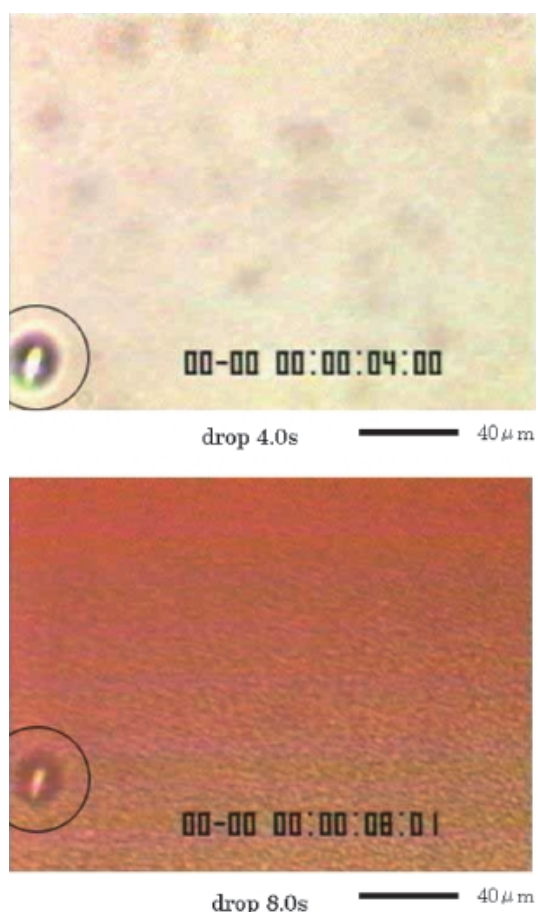

Fig. 4

Fig. 3. Comparison of start of phase-separated particle precipitation between under microgravity and under 1-g. This figure denotes the video snapshots of liquid-liquid phase separation of glass.

Fig. 4. Video snapshots of liquid-liquid phase separation of glass under microgravity (after dropping for $4.0 \mathrm{~s}$ and $8.0 \mathrm{~s}$ ). 


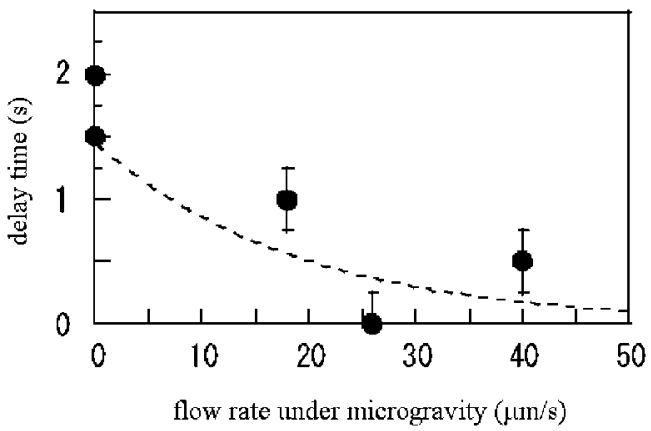

Fig. 6. Relationship between the flow rate of the melt under microgravity and delay time of phase separation under microgravity relative to the phase separation under $1-\mathrm{g}$. Flow rate evaluated from the movement of phase-separated particle. The broken line was obtained by the method of least squares.

The growth rate can be expressed as

$$
U=f \frac{D}{\lambda}\left[1-\exp \left(-\frac{\Delta S \Delta T}{R T}\right)\right],
$$

where $f$ expresses the fraction of crystal sites at which atom or molecule incorporation occurs. ${ }^{11)}$ Therefore, when there is no flow of the melt, diffusion coefficient $D$ becomes small because the concentration gradient between the phase-separated particle and the matrix seems to decrease. As a result, the nucleation rate $I_{0}$ and the growth rate $U$ decrease. When there is flow of the melt, diffusion coefficient $D$ becomes large because the concentration gradient between the phase-separated particle and the matrix seems to increase. As a result, the nucleation rate $I_{0}$ and the growth rate $U$ become higher. It is reported that the diffusion coefficient decreases by $15 \%$ regardless of the sample in the microgravity environment. ${ }^{12)}$ As a result, the nucleation rate $I_{0}$ and the growth rate $U$ decrease.

In this study, we observed that when there is no flow of the melt in the microgravity environment, the delay time is about $1.5 \mathrm{~s}$, as shown in Fig. 6. This delay seems to originate from the decrease of the diffusion coefficient due to the microgravity. When there is a flow of the melt under microgravity, this delay time approaches $0 \mathrm{~s}$ with the increase of the flow rate. This is because the diffusion coefficient seems to increase with the increase of the concentration gradient.

For crystal growth, it has been reported that nucleation and growth are retarded in a microgravity environment. ${ }^{13), 14)}$ Accordingly, nucleation and growth seem to be retarded in a microgravity environment. When there is the effect of Marangoni convection, nucleation and growth possibly depend on the delay time between the case of microgravity and 1-g and on the flow rate of the melt under microgravity.

\section{Conclusion}

We succeeded in the in situ observation of liquid-liquid phase separation of glass under microgravity of $10^{-5} \mathrm{~g}$ lasting for $10 \mathrm{~s}$. It was found that the nucleation and growth of phaseseparated particle under microgravity are slower than under $1 \mathrm{-g}$, and the delay time of phase separation between the case of microgravity and $1-\mathrm{g}$ depends on the flow rate of the melt under microgravity. These observations could be interpreted in terms of Marangoni convection and a change of diffusion.

Acknowledgment This work was supported by the Japan Space Utilization Promotion Center (JSUP).

\section{References}

1) Konishi, T., Asano, T., Ishii, Y., Soga, K., Inoue, H., Makishima, A. and Inoue, S., J. Non-Cryst. Solids, Vol. 265, pp. 19-28 (2000).

2) Macedo, P. B. and Simmons, J. H., J. Res. Natl. Bur. Stand., Vol. 78, pp. 53-59 (1974).

3) Inoue, S., Makishima, A., Inoue, H., Soga, K., Konishi, T., and Asano, T., J. Non-Cryst. Solids, Vol. 247, pp. 1-8 (1999).

4) Konishi, T., Soga, K., Inoue, H., Makishima, A., Inoue, S. and Nakano, S., J. Am. Ceram. Soc., Vol. 85, pp. 1151-1156 (2002).

5) Inoue, S., Wada, K., Nukui, A., Yamane, M., Shibata, S., Yasumori, A., Yano, T., Makishima, A., Inoue, H. and Soga, K., Phys. Chem. Glasses, Vol. 38, pp. 197-200 (1997).

6) Nakashima, K., Hayashi, K., Ohta, Y. and Morinaga, K., Mater. Trans., Vol. 32, pp. 37-42 (1991).

7) Naumann, R. J. and Herring, H. W., NASA SP-443 (1980).

8) Inoue, S., Makishima, A., Inoue, H., Soga, K., Konishi, T., Asano, T., Ishii, Y. and Koyama, M., J. Am. Ceram. Soc., Vol. 80, pp. 2413-2417 (1997).

9) Konishi, T., Asano, T., Ishii, Y., Soga, K., Inoue, H., Makishima, A., Inoue, S., Nishimura, H., Takasu, S. and Sabato, T., J. Jpn. Soc. Microgravity Appl., Vol. 17, pp. 91-97 (2000).

10) Tsukamoto, K., Onuma, K., Maruyama, S., Shimizu, K., Irisawa, T., Furukawa, Y. and Yoda, S., J. Jpn. Soc. Microgravity Appl., Vol. 11, pp. 58-70 (1994).

11) Strnad, Z., "Glass-Ceramic Materials," Elsevier, Amsterdam (1986) pp. 9-75.

12) Maruyama, S., J. Jpn. Soc. Microgravity Appl., Vol. 20, pp. 54-60 (2003) [in Japanese].

13) Maruyama, S., Miyagawa, Y., Tsukamoto, K. and Aihara, T., Transport Phenomena in Thermal Engineering, pp. 1072-1077 (1993).

14) Maruyama, S., Ohno, K., Komiya, A. and Sakai, S., J. Cryst. Growth, Vol. 245, pp. 278-288 (2002). 